\title{
Towards a Model of Urban Evolution Part II: Formal Model*
}

\author{
Mark S. Fox ${ }^{\text {ad }}$, Daniel Silver ${ }^{\text {bd }}$, Patrick Adler ${ }^{\text {cd }}$
}

November 42020

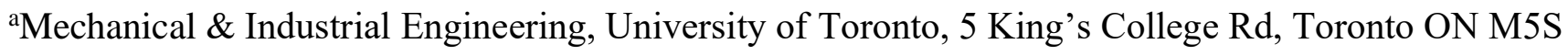
3G8, Canada

${ }^{b}$ Department of Sociology, University of Toronto Scarborough, 1265 Military Trail, Toronto, ON M1C1A4

${ }^{c}$ Rotman School of Management, University of Toronto, 105 St. George, Toronto, Ontario, M5S 3E6 Canada

${ }^{\mathrm{d}}$ School of Cities, University of Toronto, Myhal Centre, Suite 853, 55 St. George Street, Toronto, ON M5S0C9

* Please direct correspondence to dan.silver@utoronto.ca and msf@eil.utoronto.ca.

\begin{abstract}
This paper is part II of "Towards a model of urban evolution." Part I can be accessed here. This paper defines a formal model of the Signature of an urban space, comprised of: an urban genome which captures the expected groups (i.e., users) and activities (i.e., uses) of physical forms; a description of the actual activities and groups of the physical forms; and the signals that are communicated within and among urban spaces. Central to the model is a formeme, which provides the building blocks for a Signature. A formeme captures the interactions among physical forms, groups and activities. We then show how various metrics can define an urban area based on its Signature, and that these metrics can be used to measure similarity of urban spaces. The Signature and its underlying formemes capture the sources of variations in urban evolution.
\end{abstract}




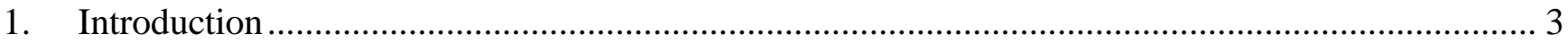

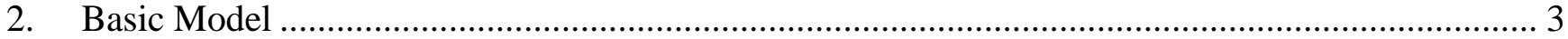

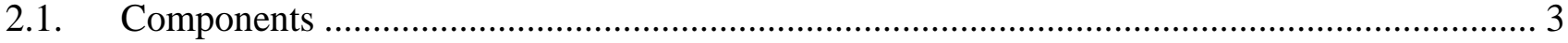

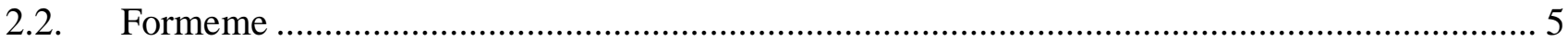

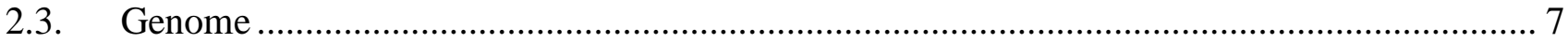

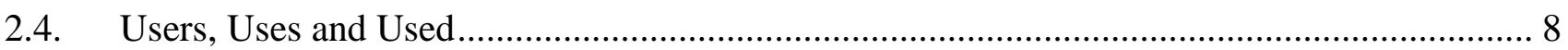

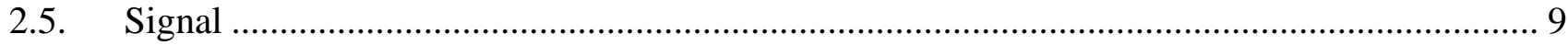

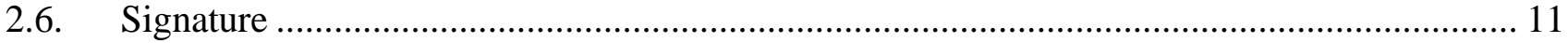

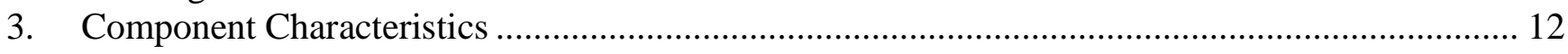

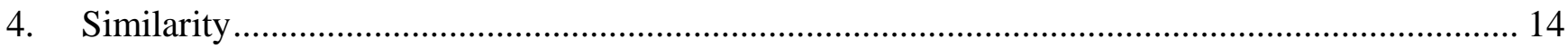

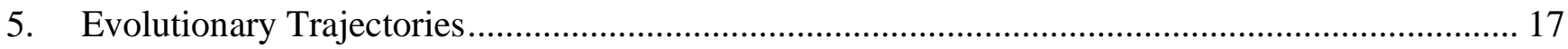

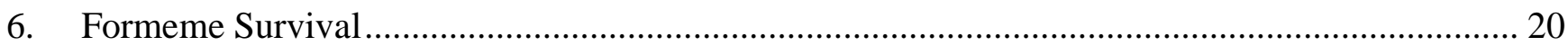

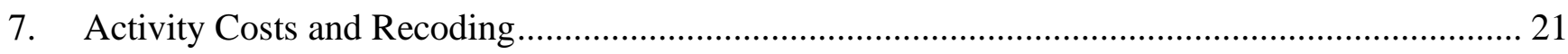

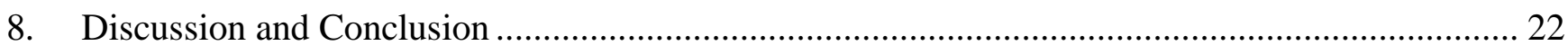

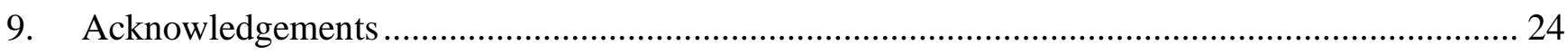

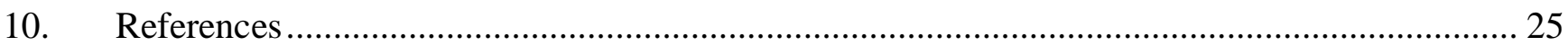




\section{Introduction}

Part I of "Towards a Model of Urban Evolution" (Silver, Fox, and Adler 2020) elaborated the broader intellectual context for our model of urban evolution. Here in Part II we define a model for encoding the key characteristics of an urban space at some time t. At the core of the model is the "formeme," the basic unit of urban evolution. A formeme is a specific encoding of urban space as a combination of physical features and the groups and activities toward which they are oriented. A formeme is $a$ way of physically organizing space for some sets of activities and groups. This definition might also be summarized as a script or set of instructions: "be made out of this stuff arranged in this way, for doing these things for groups of people like this." The cities we observe are large populations of such scripts. The complete information about the scripts encoded in a given place may be defined as its urban genome - which is itself a set of formemes. These formemes admit of variations, some of which are selected and retained. Variation, selection, and retention produce evolution, both in the sense of adaptation to local environments and the generation of historical lineages and trajectories characterized by shared, derived characteristics.

A central task of the formal model is to rigorously elaborate the intuitions behind the concepts of formeme and urban genome, and their role in the evolutionary algorithm of variation-selectionretention. Brown (2013) illustrates this general approach to formalization and theory construction in the social sciences with the example of Simon's (1952) reconstruction of Homans' exchange model. The value of such formalization comes in part in revealing the logical skeleton of informal models, but even more in identifying their key assumptions and omissions, as well as necessary auxiliaries and correctives. In the ideal case, formalization will make evident new connections and implications, and produce an "idealized" model against which empirical phenomena can be measured.

In this paper we first define the components of our model which are composed of spatial areas, physical forms, activities, and groups. We then introduce the concept of a formeme and show how it is modelled using these components. Using formemes as our basic building block, we then model the three parts of a spatial area's Signature: Urban Genome, actual uses and users, and Signals. With our model defined, we then define various metrics that can be applied to the model, and show how they can be used to measure the similarity of signatures. We finish with a discussion of questions that our model raises.

\section{Basic Model}

Our goal in this Part is to create a formal model that includes basic constituents of the urban evolutionary process, and provides a rich expressive language that can be applied and extended further.

\subsection{Components}

At the core of the model is the spatial area that is being modelled. 
C: the set of all spatial areas in the domain.

Members of $\mathrm{C}$ can be spatially related using standard geo-spatial primitives. A model can be created for any member of $\mathrm{C}$, allowing for the modelling of an urban area at different levels of aggregation and alternative spatial boundaries. Figure 1 depicts a hierarchical structuring of the members of $\mathrm{C}$ for the City of Toronto. We can model the City at varying levels of spatial aggregation.

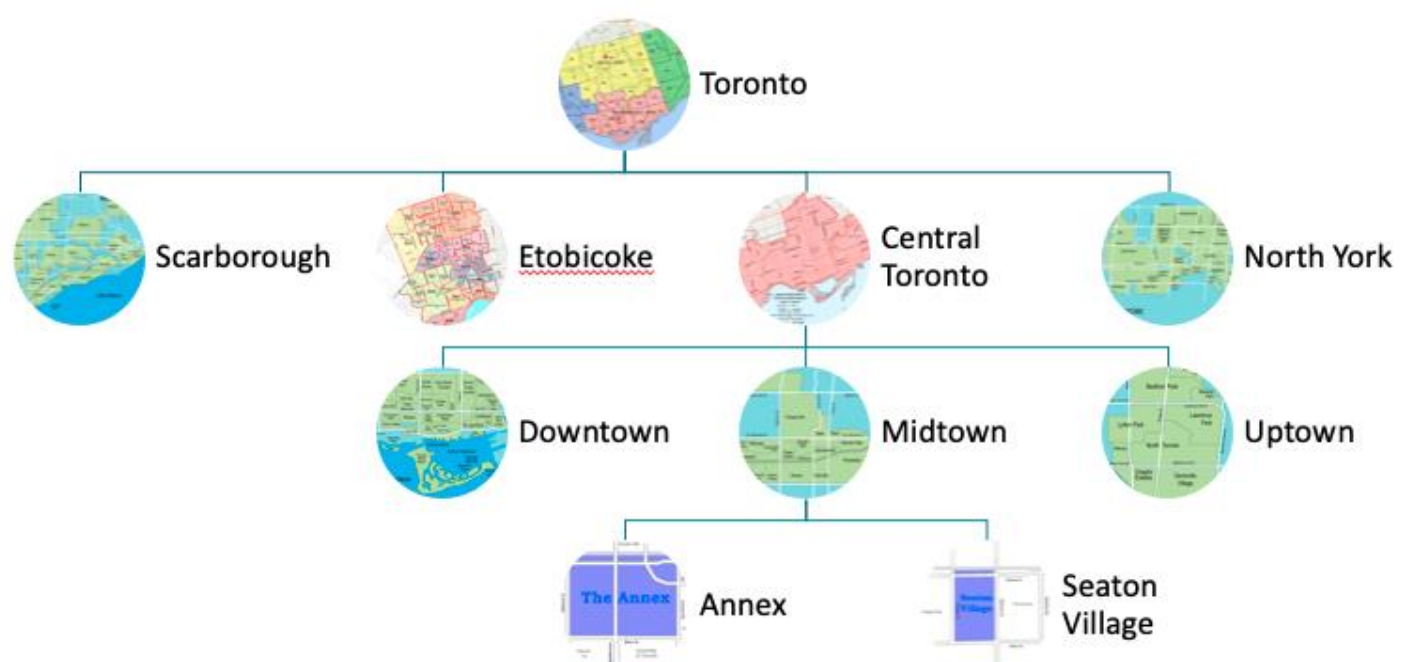

Figure 1: Hierarchical Aggregation of Spatial Areas in the City of Toronto

Our model of a spatial area $\mathrm{C}$ is comprised of three "components":

P: the set of all possible types of physical forms in the domain

A: the set of all possible types of activities (uses) in the domain.

G: the set of all possible types of groups (users) in the domain.

Any member of a component is referred to as an element (e). For example, a warehouse is an element of the component $\mathrm{P}$. The elements of each component determine how expressive the model will be. For example, if "vehicle" is an element of $\mathrm{P}$, but it does not include any types of vehicles, then the model cannot differentiate among different types of vehicles. On the other hand if "bus", "subway", "car", and "truck" are elements of P, then the model can support a more nuanced representation and analysis of an urban area. By restricting the elements within a component, the nature of the analysis is in turn restricted. For example, one could restrict the components to focusing solely on eating, including restaurants and groceries, and the groups of people and activities associated with them. 

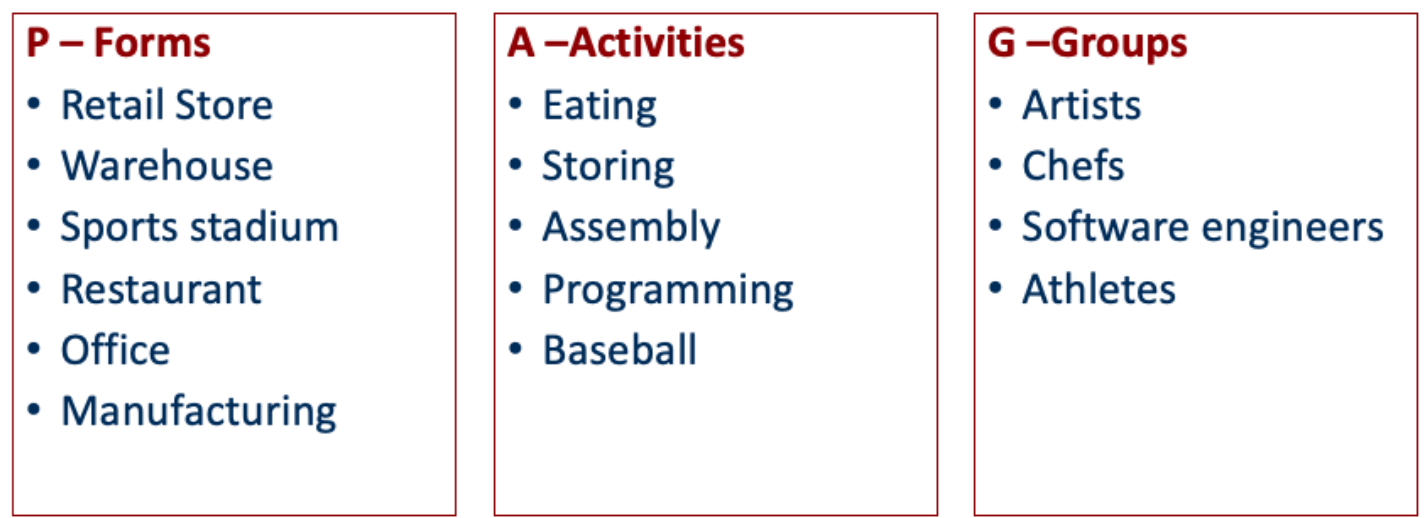

Figure 2: Example Component Elements

\subsection{Formeme}

Central to our model is the recognition that $\mathrm{P}, \mathrm{A}$ and $\mathrm{G}$ are interdependent. Forms enable activities performed by groups. But the relationship is not uni-directional. Groups impose their own interpretation of forms in order to carry out activities for which the forms may not have been designed. This makes the forms subject to evolutionary processes, as new uses accumulate upon or transform the old.

To capture the relationship among elements of $\mathrm{P}, \mathrm{A}$ and $\mathrm{G}$, we introduce the concept of formeme. Formemes encode the information in a space, enabling their replication elsewhere, their maintenance into the future, or their recoding into new configurations. The formeme concept extends the concept of the "meme" to the urban domain. "Memes" are, in simple terms, "ideas that spread" or "information worth copying." 1 The "meme" in "formeme" highlights that the information encoded in cities can be copied and retained - formemes are "free-floating rationales" (Dennett, 2017) for how to organize space, which can be picked up and applied elsewhere. They can be encoded in artifacts and institutions as well as in human beings' habits or routines. If one space is programmed to "be made out of this stuff, for these people, doing these things," another can as well -- to some degree of fidelity, via some mechanisms of communication and inheritance (the exact degree and process is an empirical question, and will affect the nature of the evolutionary sequences that follow). For example, the cul-de-sac was deployed in English Garden City designs at the beginning of the twentieth century, and then appeared in many areas thereafter; it is an urban idea that spread. The cul-de-sac is a relatively successful formeme, both in terms of how far it has spread and the fidelity of its copies.

A Formeme $\mathrm{f}$ is defined to be a triple composed of $\mathrm{P}, \mathrm{A}$ and $\mathrm{G}$.

$$
\mathrm{f}=\langle\mathrm{f}[\mathrm{p}], \mathrm{f}[\mathrm{a}], \mathrm{f}[\mathrm{g}]>\text { where } \mathrm{f}[\mathrm{p}] \subseteq \mathrm{P} \wedge \mathrm{f}[\mathrm{g}] \subseteq \mathrm{G} \wedge \mathrm{f}[\mathrm{a}] \subseteq \mathrm{A}
$$

$\mathrm{f}[\mathrm{p}]$ can be understood as a way of encoding space with a physical design, which we might summarize "be made out of this stuff arranged in this way." For a building, a very crude characterization of $\mathrm{f}[\mathrm{p}]$

\footnotetext{
${ }^{1}$ A somewhat fuller definition would be: "information such as knowledge, beliefs, and values that is inherited through social learning and expressed in behavior and artifacts" (Mesoudi, Whiten and Laland 2004).
} 
could refer to being made out of brick and steel with long-span floor spaces. The more areas that are programmed in this way, the more prevalent this variant of $f[p]$ has become.

These sorts of physical properties are not the only information encoded in an area. It is programmed for somebody to do something. A very similar physical space made out of brick and steel could be for shipping and receiving by employees with certain occupational credentials or for late-night entertainment venue by dancing enthusiasts. Our model seeks to capture this additional information with the terms $f[a]$ and $f[g]$. $f[a]$ and $f[g]$ can be understood as ways of coding space in terms of what and who it is for: "be a place for doing these things $f[a]$ for groups of people like this (f[g])." F[a] and $\mathrm{f}[\mathrm{g}]$ can be manifest in a number of ways. This information may be explicit, in a zoning designation (for industrial or entertainment), a sign on the wall ("only employees may enter"), or a dress code and drink minimum. The information may also be implicit, in an array of signs and cues that indicate who is and is not supposed to be there, and what they should and should not be doing. These are the "iss and oughts" of urban life.
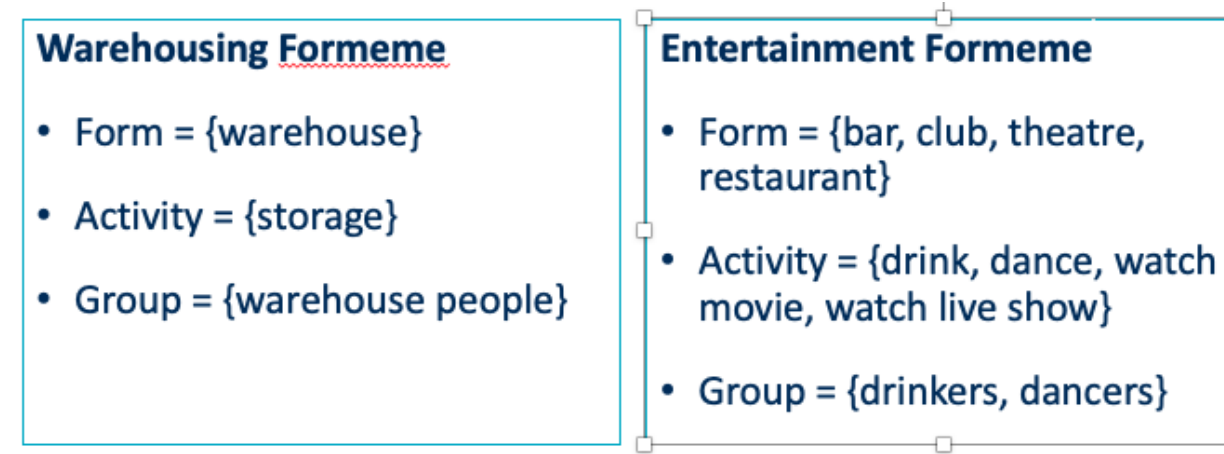

\section{Figure 3: Example Formemes}

We define the predicate Formeme to denote that a particular $\mathrm{f}$ is a formeme:

Formeme(f) is true if $\mathrm{f}[\mathrm{p}] \subseteq \mathrm{P} \wedge \mathrm{f}[\mathrm{g}] \subseteq \mathrm{G} \wedge \mathrm{f}[\mathrm{a}] \subseteq \mathrm{A}$.

$\mathcal{F}$ : the powerset of all possible formemes, i.e., combinations of $\mathrm{P}, \mathrm{G}$ and $\mathrm{A}$

$$
=\{\langle\mathrm{p}, \mathrm{g}, \mathrm{a}\rangle \mid \mathrm{p} \subseteq \mathrm{P} \wedge \mathrm{g} \subseteq \mathrm{G} \wedge \mathrm{a} \subseteq \mathrm{A}\}
$$

We define the predicate SubFormeme which is true if one formeme is a subset of another:

$$
\text { SubFormeme }\left(f, f^{\prime}\right)=f[p] \subseteq f^{\prime}[p] \wedge f[g] \subseteq f^{\prime}[g] \wedge f[a] \subseteq f^{\prime}[a]
$$

Finally, we define a primitive formeme as a formeme that has at most one element for each of $f[p], f[g]$ and $\mathrm{f}[\mathrm{a}]$.

$$
\operatorname{primFormeme}(\mathrm{f})=|\mathrm{f}[\mathrm{p}]| \leq 1 \wedge|\mathrm{f}[\mathrm{g}]| \leq 1 \wedge|\mathrm{f}[\mathrm{a}]| \leq 1
$$




\subsection{Genome}

The Genome of a spatial area captures its physical forms and the activities and groups toward which they are oriented. It codifies the evolution of a spatial area at some time t. It defines the expected uses of the urban form in terms of the activities to be performed and the groups who are to perform them.

We define a genome $\mathrm{U}$ as a set of Formemes:

$$
\mathrm{U}=\{\mathrm{u} \mid \text { Formeme }(\mathrm{u})\}
$$

Expressed another way, $\mathrm{U}$ is a subset of the powerset of Formemes: $\mathrm{U} \subseteq \mathcal{F}$

We define

$$
\begin{aligned}
& u_{i}: \text { the } i^{\text {th }} \text { formeme in } U \\
& u_{i}[p] \text { : the set of forms in the } i^{\text {th }} \text { formeme in } U \\
& u_{i}[a] \text { : the set of activities in the } i^{\text {th }} \text { formeme in } U \\
& u_{i}[g] \text { : the set of groups in the } i^{\text {th }} \text { formeme in } U
\end{aligned}
$$

and

$$
\begin{aligned}
& \mathrm{U}[\mathrm{p}]=\bigsqcup_{i} \mathrm{u}_{i}[\mathrm{p}] \text { set of all forms in } \mathrm{U} \\
& \mathrm{U}[\mathrm{a}]=\bigsqcup_{\mathrm{i}} \mathrm{u}_{i}[\mathrm{a}] \text { set of all activities in } \mathrm{U} \\
& \mathrm{U}[\mathrm{g}]=\bigsqcup_{\mathrm{i}} \mathrm{u}_{\mathrm{i}}[\mathrm{g}] \text { set of all groups in } \mathrm{U}
\end{aligned}
$$

Figure 4 depicts two examples of genomes. The first genome describes a light industrial zone composed of three formemes. $\mathrm{u} 1$ describes warehousing usage, $\mathrm{u} 2$ describe manufacturing usage, and u3 described service usage. All three co-occur within the same spatial area. The second genome is also composed of 3 formemes describing entertainment related forms, users and activities, all existing/occurring in the same spatial area.

\begin{tabular}{|l}
\hline Light Industrial zone \\
- u1 $=<\{$ warehouse $\}$, \\
\{storage\}, \\
\{warehouse people\} $>$ \\
- u2 = $<$ \{manufacturing \\
building\}, \\
\{light manufacturing\}, \\
\{manufacturing people $\}>$ \\
- u3 = $<$ sservice building\}, \\
\{industrial services\}, \\
\{industrial services people $\}>$
\end{tabular}

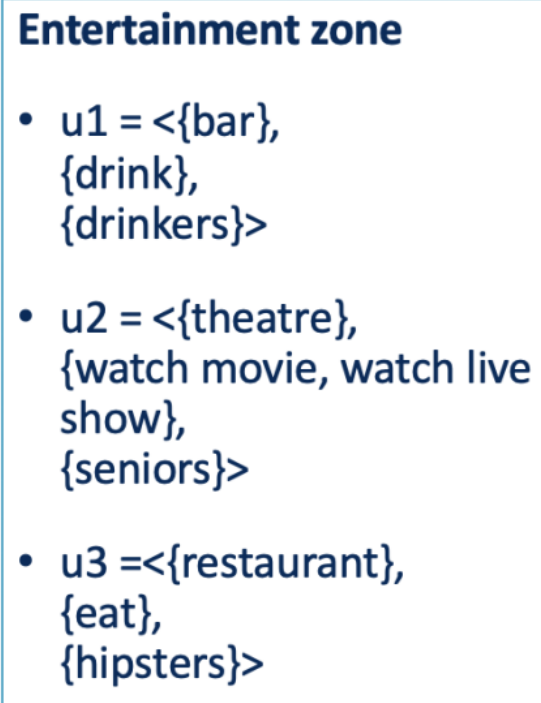

- $\mathrm{u} 2=<\{$ theatre $\}$, \{watch movie, watch live show\}, \{seniors\}>

- u3 $=<\{$ restaurant $\}$, \{eat\}, \{hipsters\}>

Figure 4: Example Genomes 
We define the Urban Genome as tying a specific genome $\mathrm{U}$ to a spatial location $c$, at time $t$ :

Genome(c, t, U, w) where

c: denotes a spatial area

$\mathrm{t}$ : denotes the time at which the genome describes $\mathrm{c}$

$\mathrm{w}$ : denotes the world in which U exists. [In most cases, we will omit this parameter, but when we need to compare alternative scenarios for the same space $\mathrm{c}$ and time $\mathrm{t}, \mathrm{w}$ will be used to distinguish them (i.e., alternative worlds)].

In this document we use the function $\mathrm{UG}$ to denote the set of formemes for a specific spatial area $\mathrm{c}$ and time t:

$$
\mathrm{UG}(\mathrm{c}, \mathrm{t})=\mathrm{U}=\{\mathrm{u} \mid \text { Formeme}(\mathrm{u})\} \text { for a space } \mathrm{c} \text { at time } \mathrm{t}
$$

in other words $\mathrm{c}$ and $\mathrm{t}$ uniquely identify a specific genome.

\subsection{Users, Uses and Used}

If the genome describes the way a space is organized physically and for certain uses and users, it does not determine that it will in fact be used that way. A particular urban spatial configuration cannot reproduce, replicate, or recode itself. It requires human users to maintain, copy, or change it though their actual performance of some activities. Hence we refer to $\mathrm{H}$ as the Usage Genome: the actual as opposed to expected uses, users, and things they use. This introduces the beginning of a dynamic component to the model, representing the process of actually receiving, interpreting, utilizing, and potentially modifying or reproducing the information encoded in the urban genome. This dynamism will be crucial for a model of urban evolution, as it is a central source of novel variations, their differential reproduction, and their degrees of retention.

We define the Usage Genome, i.e., uses, users and what they use, as a set of Formemes H. Just like the urban genome $\mathrm{U}$, formemes are also the primitive "material" used to construct $\mathrm{H}$, as each focuses on the relationship between form, activity, and groups. Where $\mathrm{U}$ is the formetic information encoded in an area's physical forms, $\mathrm{H}$ is the formetic information encoded in its human users' customs, practices, routines, and modes of interpretation. $\mathrm{U}$ is what the space expects from its users; $\mathrm{H}$ is what the people expect from their spaces.

$$
H=\{h \mid \text { Formeme }(h)\}
$$

Expressed another way, $\mathrm{H}$ is a subset of the powerset of Formemes: $\mathrm{H} \subseteq \mathcal{F}$

We define

$\mathrm{h}_{\mathrm{i}}$ : the $\mathrm{i}^{\text {th }}$ formeme in $\mathrm{H}$

$h_{i}[p]$ : the set of physical forms in the $\mathrm{i}^{\text {th }}$ formeme in $\mathrm{H}$

$h_{i}[a]$ : the set of activities in the $i^{\text {th }}$ formeme in $\mathrm{H}$

$h_{i}[g]$ : the set of groups in the $i^{\text {th }}$ formeme in $\mathrm{H}$ 
and

$$
\begin{aligned}
& H[p]=\bigsqcup_{i} h_{i}[p] \text { set of all forms in } H \\
& H[a]=\bigsqcup_{i} h_{i}[a] \text { set of all activities in } H \\
& H[g]=\bigsqcup_{i} h_{i}[g] \text { set of all groups in } H
\end{aligned}
$$

In this document we use the function $\mathrm{HG}$ to denote the set of formemes for a specific spatial area $\mathrm{c}$ and time t:

$$
\mathrm{HG}(\mathrm{c}, \mathrm{t})=\mathrm{H}=\left\{\mathrm{h}_{\mathrm{i}} \mid \text { formeme }\left(\mathrm{h}_{\mathrm{i}}\right)\right\} \text { that exist for some space } \mathrm{c} \text { at time } \mathrm{t}
$$

Figure 5 represents the transformation of a light industrial zone. The formeme $\mathrm{h} 3$ depicts that the actual use and users of a warehouse now includes hipsters dancing. This formeme co-exists with the traditional uses of the area.

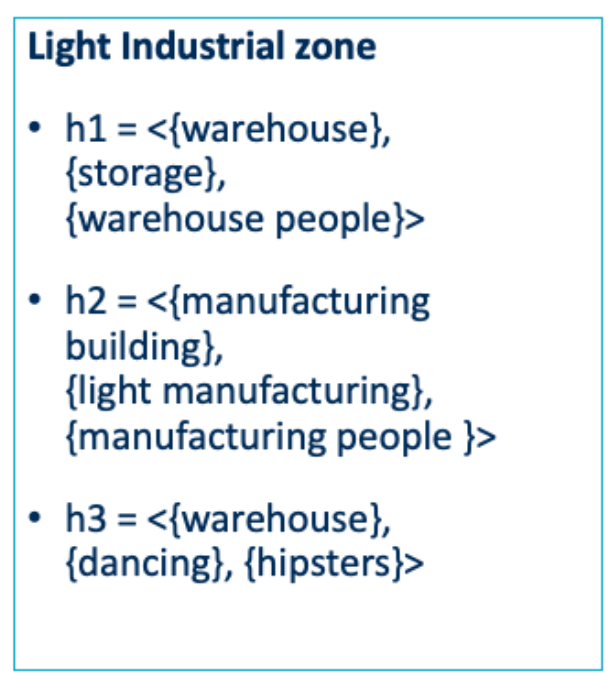

\section{Figure 5: Formemes in $\mathbf{H}$}

\subsection{Signal}

Signals are crucial features of an urban evolutionary model. Any code must be communicated via some mechanism and we call that mechanism the Signal (S). Potential users can access the relevant urban information encoded in the genome only if that information can be transmitted to them via a method they can interpret. Characteristics invisible to potential users are unlikely to survive, while those that reach a broad audience may have a better chance of recruiting users and being replicated elsewhere.

We define $\mathrm{S}$ to be a set of signals received and processed within the spatial area $\mathrm{c}$, where each signal is composed of a 
- Formeme that communicates a fragment of a genome. This fragment may be assimilated by another spatial area, first as a change to $\mathrm{H}$, and if it survives, eventually as a change to $\mathrm{U}$;

- method of communication. A Formeme may be communicated in more than one way, and depending on the method of communication, the signal may travel only within c (intra-spatial signal), or between c's (inter-spatial signal), or both (bi-spatial signal); and

- the number of times the signal has been received. A signal that is received with a high frequency may be have a higher probability of assimilation in $\mathrm{H}$.

$\mathrm{S}=\left\{\mathrm{si}_{\mathrm{i}} \mid \mathrm{Si}_{\mathrm{i}}=\langle\mathrm{f}, \mathrm{cm}, \mathrm{n}>\wedge\right.$ Formeme$(\mathrm{f}) \wedge \mathrm{cm} \in \mathrm{CM} \wedge$ integer(n) $\}$

where

$\mathrm{CM}$ is the set of communication methods

$\mathrm{n}$ is the number of times the $\mathrm{F}$ has been received

We define:

$\mathrm{S}_{\mathrm{i}}:$ the $\mathrm{i}^{\text {th }}$ signal in $\mathrm{S}$

$\mathrm{si}_{\mathrm{i}}[\mathrm{f}]$ : is the Formeme $\mathrm{f}$ of the $\mathrm{i}^{\text {th }}$ signal

$\mathrm{si}[\mathrm{cm}]$ : is the communication methods of the $\mathrm{i}^{\text {th }}$ signal

$\mathrm{Si},[\mathrm{n}]$ : is the frequency of the $\mathrm{i}^{\text {th }}$ signal

and

$\mathrm{S}[\mathrm{p}]=\bigsqcup_{\mathrm{i}} \mathrm{s}_{\mathrm{i}}[\mathrm{f}][\mathrm{p}] \quad$ set of all forms in $\mathrm{S}$

$\mathrm{S}[\mathrm{a}]=\bigsqcup_{\mathrm{i}} \mathrm{si}_{\mathrm{i}}[\mathrm{f}][\mathrm{a}] \quad$ set of all activities in $\mathrm{S}$

$\mathrm{S}[\mathrm{g}]=\bigsqcup_{\mathrm{i}} \mathrm{Si}[\mathrm{f}][\mathrm{g}] \quad$ set of all groups in $\mathrm{S}$

$\mathrm{S}[\mathrm{f}]=\bigsqcup_{\mathrm{i}} \mathrm{Si}_{\mathrm{i}}[\mathrm{f}] \quad$ set of all formemes in $\mathrm{S}$

A Valid Signal $\mathrm{si}$ satisfies the following requirements:

1. Formeme Validity: Formeme $\left(\mathrm{s}_{\mathrm{i}}[\mathrm{f}]\right)$ is true.

2. Genome Validity: Given the originating genome $U G(c, t)$ for the signal $\exists \mathrm{j} \mathrm{u}_{\mathrm{j}} \in \mathrm{UG}(\mathrm{c}, \mathrm{t}) \wedge$ SubFormeme $\left(\mathrm{s}_{\mathrm{i}}[\mathrm{f}], \mathrm{u}_{\mathrm{j}}\right)$

3. Signal Method Validity: $\mathrm{s}_{\mathrm{i}}[\mathrm{cm}] \subseteq \mathrm{CM}$ (where $\mathrm{CM}$ is the set of all methods)

For a dance club, signal methods could include informal word of mouth chatter about what is happening Friday night, but also advertising and social media. For example, a Yelp review page tells potential users what is there, transmits information about what kind of ambiance to expect, price, location, typical users, and directs one to other websites to find out what is happening and when. For a roadway, traffic signage could be the Signal, as well as radio traffic reports or apps such as Google Maps or Waze. The sign on the dance club therefore has two parts: the physical form which is a constituent of the club's $f[p]$ and the signal projected within or from this form.

Another interesting aspect of the model is that it can represent methods of communication used (or not) within a spatial area c, which may not be those used in signals to other areas. For example, China bans the use of Google services within its boundaries, but may use it in signals to other countries. 
An illustration of the role of signalling in urban evolution is the proliferation of coffee shops in Seoul, South Korea. We can imagine that the growth of coffee chains in North America, such as Starbucks, led to signals containing the formeme:

$$
\begin{aligned}
& \mathrm{f}[\mathrm{p}]=\text { coffee } \text { shop design } \\
& \mathrm{f}[\mathrm{a}]=\text { drinking coffee, } \text {, socializing } \\
& \mathrm{f}[\mathrm{g}]=\text { GenX, Millenials }
\end{aligned}
$$

Assuming a method of transmission such as Korean tourists visiting North America discovering/enjoying Starbucks, and returning home with this signal in their minds, the signal directly impacts $\mathrm{H}$ by changing the activities (i.e., drinking coffee, socializing) of the relevant groups (ie., GenX, Millenials). This results in the construction of coffee shops whose design is based on the signal. Over time, these coffee shops will modify the genome for the area c they appear in.

Inter-spatial signals not only represent genome fragments from other spatial locations, but they can represent the broader spatial area which the recipient of the signal is part of. This wider signal is a way to represent the surrounding environment as the messages locals receive from the broader context in which they are situated. For example the city, state and country act as a source of environmental signals for a neighbourhood that is embedded in them, The environment may have a significant impact on $\mathrm{H}$, affecting the evolutionary path of a genome. This environment is constituted generally by very abstract ideas about how to organize space, which can be embedded in cultural, political, and natural systems. For instance, broad cultural values concerning gender relations inform models of how to design houses and public spaces. Ancient Greek cities were laid out to emphasize democratic egalitarianism (Shipley, 2005). Religious concepts have similarly structured the arrangement of space, for instance in palatial centers or how the position of Arabic-Islamic cities was designed using the Fiqh paradigm, which was an attempt to express religious principles through urban form (Hakim,1986). The environment will often exert selection pressures upon people within it, which will in turn affect the probability of a given lower-order formeme or genome propagating there. However, the reverse is possible: lower order formemes can promote an environment conducive to their own success. This is an urban variant of niche formation.

\subsection{Signature}

To complete the definition of the basic terms in our model, we introduce the notion of a Signature. The signature combines the aforementioned concepts to provide a complete representation of a spatial area at some time t. It tells us what the spatial area was geared toward, i.e., the genome, the orientations of its actual users, uses and what is used (forms), and the formemes received as signals.

$$
\text { Signature(c, t, U, H, S, w) }
$$

We can now define the function:

$$
\begin{aligned}
& \mathrm{SIG}(\mathrm{c}, \mathrm{t}, \mathrm{w})=\langle\mathrm{U}, \mathrm{H}, \mathrm{S}> \\
& \text { in other words, the complete signature for space } \mathrm{c} \text { at time } \mathrm{t}
\end{aligned}
$$




\section{Component Characteristics}

Any element can have zero or more attributes. For example, the number of the same elements, e.g., the number of restaurants, eating activities, and chefs, may be an important characteristic of a spatial area. Since, the size or number of a type of element is important, we define:

size $(\mathrm{c}, \mathrm{t}, \mathrm{e})$ : is a function that returns the quantity of instances of e at spatial location $c$ at time $t$, where $\mathrm{e} \in \mathrm{P} \cup \mathrm{A} \cup \mathrm{G}$. If $e$ is an activity, it can represent the number of occurrences of that activity up to time $t$. If e is a group, it can represent the number of people in the group at time $\mathrm{t}$.

Usize $(c, t, e)$ : is $\operatorname{size}(c, t, e)$ for e $\in U$.

$\operatorname{Hsize}(\mathrm{c}, \mathrm{t}, \mathrm{e})$ : is $\operatorname{size}(\mathrm{c}, \mathrm{t}, \mathrm{e})$ for $\mathrm{e} \in \mathrm{H}$.

Fsize(F, 3): is the quantity of instances of e in a set of formemes $F$

Another attribute of interest is the value associated with an element. For example, the value of a building, parcel of land, the assets of a group, or perhaps value associated with the ability to perform an activity. We define:

value $(\mathrm{c}, \mathrm{t}, \mathrm{e})$ : is a function that returns the value of $e$ at spatial location $c$ at time $t$ where e $\in \mathrm{P}$ $\cup \mathrm{A} \cup \mathrm{G}$.

\section{Signal characteristics}

Signals may vary in the impact on changing the formemes in a Signature. In this section we focus on measuring the characteristics of $\mathrm{S}$ that lead to variations in impact.

Signal Reach. The characteristic reach refers to the percentage of the population that is able to receive and process signal $\mathrm{s}$ within $\mathrm{c}$ at time $\mathrm{t}$.

reach $(\mathrm{s}, \mathrm{c}, \mathrm{t}): \%$ of population within $\mathrm{c}$ at time $\mathrm{t}$ that receive and can process the signal.

Not all signals reach the target population within c. Not everyone follows twitter, or has a facebook page. Marketing emails have a notoriously low percentage that are actually opened. While electronic communications may have great speed, and cover large distances, their reach may be minimal.

Similarly, the reach across spatial areas will differ. Some areas are more attuned to social media than others, leading to differences in reach. This naturally leads to further differentiation of reach by group:

reachG(s, c, t, g): \% of a group $\mathrm{g}$ within spatial area $\mathrm{c}$ at time $\mathrm{t}$ that receive and can process the signal.

Signal Audience and Precision. Signals have a target audience. This is the groups within c for whom they are targeted. 
audienceG(s, c, t, g): denotes the signal s has a target audience of group $\mathrm{g}$ at time $\mathrm{t}$

Precision refers to the percentage of audience that receive and processes the signal.

precisionG $(\mathrm{s}, \mathrm{c}, \mathrm{t}, \mathrm{g})$ : the percentage of group $\mathrm{g}$ in spatial area $\mathrm{c}$ at time $\mathrm{t}$ that is able to process the signal.

While a signal may have a large reach, its precision can be low as it may not be reaching the audience to which it is directed. Consider a by-law that prohibits BBQs at parks that is posted at each park versus one that only appears in the municipality's records. The former has greater reach than the latter, assuming that municipal records are seen by very few residents. On the other hand, a general sign at the park that prohibits the use of flammable devices versus BBQs, will have lower precision than the latter, as some people may not interpret a flammable device as including a BBQ.

Signal Clarity. The characteristic clarity refers to the probability that the receiving group will correctly interpret the content of the signal.

clarityG(s, c, t, g): probability that the recipient group g will correctly interpret the content of the signal $\mathrm{s}$ in spatial area $\mathrm{c}$ at time $\mathrm{t}$.

Consider the BBQ bylaw again. A sign posted at a park stating "no fires" is less clear than a sign that states "no fires, including BBQs".

Signal Noise. The characteristic noise refers to the degradation of the signal over distance and/or time. ${ }^{2}$ In particular, if signal s conveys a formeme $\mathrm{f}$, then noise mutates $\mathrm{f}$ into $\mathrm{f}$ '.

noise( $\mathrm{s}, \mathrm{c} 1, \mathrm{t} 1, \mathrm{c} 2, \mathrm{t} 2)$ : percentage of the signal s content that mutates in transmission from spatial area $\mathrm{c} 1$ at time $\mathrm{t} 1$ to spatial area $\mathrm{c} 2$ at time $\mathrm{t} 2$.

How to compute the percentage of noise is an open question. One approach is to determine the $\%$ of the transmitted portion of $\mathrm{f}$ that is changed. This assumes some type of encoding where differences can be computed.

Signal noise and clarity introduces another dynamic element to the framework, because it allows for the strategic deployment of signals by actors who wish to misdirect or jam signals. Indeed, opportunistic actors can appropriate signals and misdirect them from their 'natural' state.

Signal Frequency. The frequency with which information about a formeme is received can determine its effect on the Usage Genome (HG); more frequent signals may have a higher probability of altering

\footnotetext{
2 In classical Shannonian information theory, a signal can vary in two main ways, noise and cost. Noise refers to anything that interferes with and degrades a signal, and cost refers to difficulties in encoding and decoding information that reduce transmission speed.
} 
HG. We first have to know what signals are received by spatial area. We define receivedSignals as the set of signals received by a spatial area c during the time interval $\left[\mathrm{t}, \mathrm{t}^{\prime}\right]$ :

receivedSignals $\left(c, t, t^{\prime}\right)$ is the set of signals received by location $\mathrm{c}$ between $\mathrm{t}$ and $\mathrm{t}^{\prime}$

and the signals sent by a spatial area $\mathrm{c}$ during time interval $\left[\mathrm{t}, \mathrm{t}^{\prime}\right]$ :

sentSignals $\left(c, t, t^{\prime}\right)$ is the set of signals sent by location c between $t$ and $t^{\prime}$

We can define the frequency of a formeme found in receivedSignals:

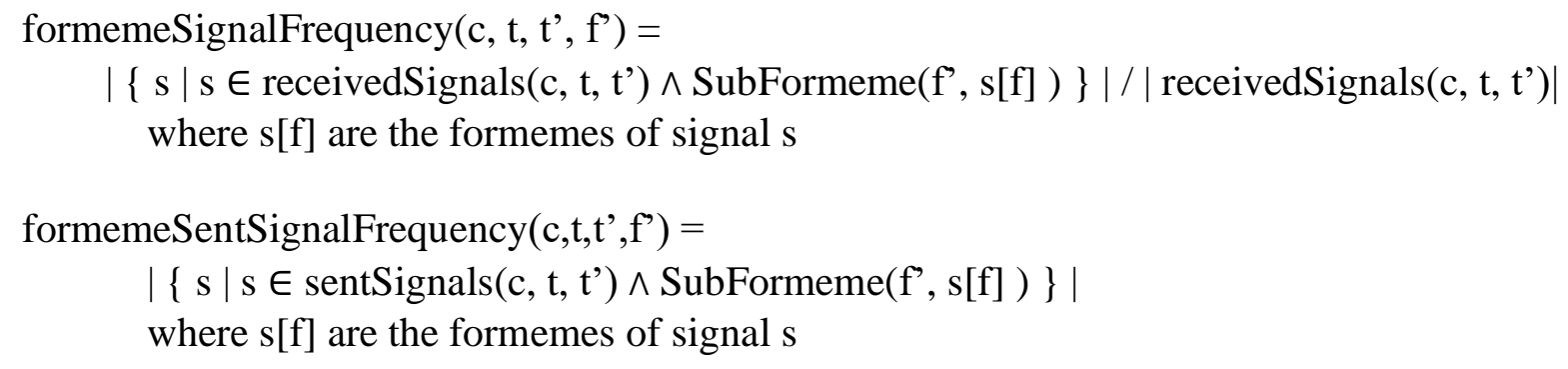

\section{Similarity and Formetic Distance}

An important concept in modelling urban evolution is the degree to which formemes are similar. By similarity, we mean the degree to which they share the same elements: forms, activities, and groups. The hypothesis is the more similar the genomes, the more similar the evolutionary path. But if similar genomes diverge over time, what are the key differences in elements that lead to the change?

We introduce the function fdist that returns the formetic distance between two formemes.

$\operatorname{fdist}\left(\mathrm{f}_{1}, \mathrm{f}_{2}\right)$ : measures the formetic distance between formemes $\mathrm{f}_{1}$ and $\mathrm{f}_{2}$.

The smaller the value, the more similar the formemes are. There can be many different distance metrics. fdist() is minimally ordinal. We constrain the definition of fdist as follows:

$$
\begin{array}{ll}
\text { Axiom 1: Reflexivity } & \operatorname{fdist}\left(\mathrm{f}_{1}, \mathrm{f}_{1}\right)=0 \\
\text { Axiom 2: Symmetry } & \operatorname{fdist}\left(\mathrm{f}_{1}, \mathrm{f}_{2}\right)=f \operatorname{dist}\left(\mathrm{f}_{2}, \mathrm{f}_{1}\right) \\
\text { Axiom 3: Subadditivity } & \operatorname{fdist}\left(\mathrm{f}_{1}, \mathrm{f}_{2}\right)+\operatorname{fdist}\left(\mathrm{f}_{2}, \mathrm{f}_{3}\right) \geq \operatorname{fdist}\left(\mathrm{f}_{1}, \mathrm{f}_{3}\right)
\end{array}
$$

One possible definition of fdist is based on the total number of elements common to both formemes, divided by the total number of unique elements:

$$
\operatorname{bfdist}\left(f_{1}, f_{2}\right)=\quad 1-\frac{\left|f_{1}[p] \cap f_{2}[p]\right|+\left|f_{1}[a] \cap f_{2}[a]\right|+\left|f_{1}[g] \cap f_{2}[g]\right|}{\left|f_{1}[p] \cup f_{2}[p]\right|+\left|f_{1}[a] \cup f_{2}[a]\right|+\left|f_{1}[g] \cup f_{2}[g]\right|}
$$


In order to measure how similar urban genomes are, we define the distance between two sets of Formemes $F_{1}$ and $F_{2}$ :

$\operatorname{Fdist}\left(F_{1}, F_{2}\right)$ : measures the similarity between formeme sets $F_{1}$ and $F_{2}$.

The smaller the value, the more similar the formeme sets are. There can be many different distance metrics. Fdist() is minimally ordinal. We constrain the definition of Fdist() as follows:
Axiom 1: Reflexivity
Fdist $\left(\mathrm{F}_{1}, \mathrm{~F}_{1}\right)=0$
Axiom 2: Symmetry
Fdist $\left(F_{1}, F_{2}\right)=$ Fdist $\left(F_{2}, F_{1}\right)$
Axiom 3: Subadditivity
$\operatorname{Fdist}\left(\mathrm{F}_{1}, \mathrm{~F}_{2}\right)+\operatorname{Fdist}\left(\mathrm{F}_{2}, \mathrm{~F}_{3}\right) \geq \operatorname{Fdist}\left(\mathrm{F}_{1}, \mathrm{~F}_{3}\right)$

One possible definition of Fdist() counts the number of element types shared between the formeme sets divided by the total number of element types across both formeme sets.

$$
\operatorname{bFdist}\left(F_{1}, F_{2}\right)=1-\frac{\left|F_{1}[p] \cap F_{2}[p]\right|+\left|F_{1}[a] \cap F_{2}[a]\right|+\left|F_{1}[g] \cap F_{2}[g]\right|}{-a F_{1}[p] \cup F_{2}[p]|+| F_{1}[a] \cup F_{2}[a]|+| F_{1}[g] \cup F_{2}[g] \mid}
$$

Using bFdist, we can visualize the evolutionary trajectories of the genomes of various spatial areas, i.e., bFdist $\left(\mathrm{U}_{1}, \mathrm{U}_{2}\right)$. Figure 6 illustrates urban change in terms of the reproduction of urban genomes over time. Since moving up on the $\mathrm{Y}$-axis represents the passage of time, the evolutionary lineage of different ' $c$ ' can be traced by following a particular trajectory upwards. Along the X-axis, the diagrams provide a simplified means of genomic similarity between different ' $c$ '. Since proximity on the X-axis indicates a high degree of similarity, the diagram can be interpreted as representing the increasing differentiation of a set of spatial areas over time. Within this overall differentiation, characteristics such as pace, stability/volatility, and convergence/divergence (discussed in Part 3) govern the development of each individual ' $c$ '. 


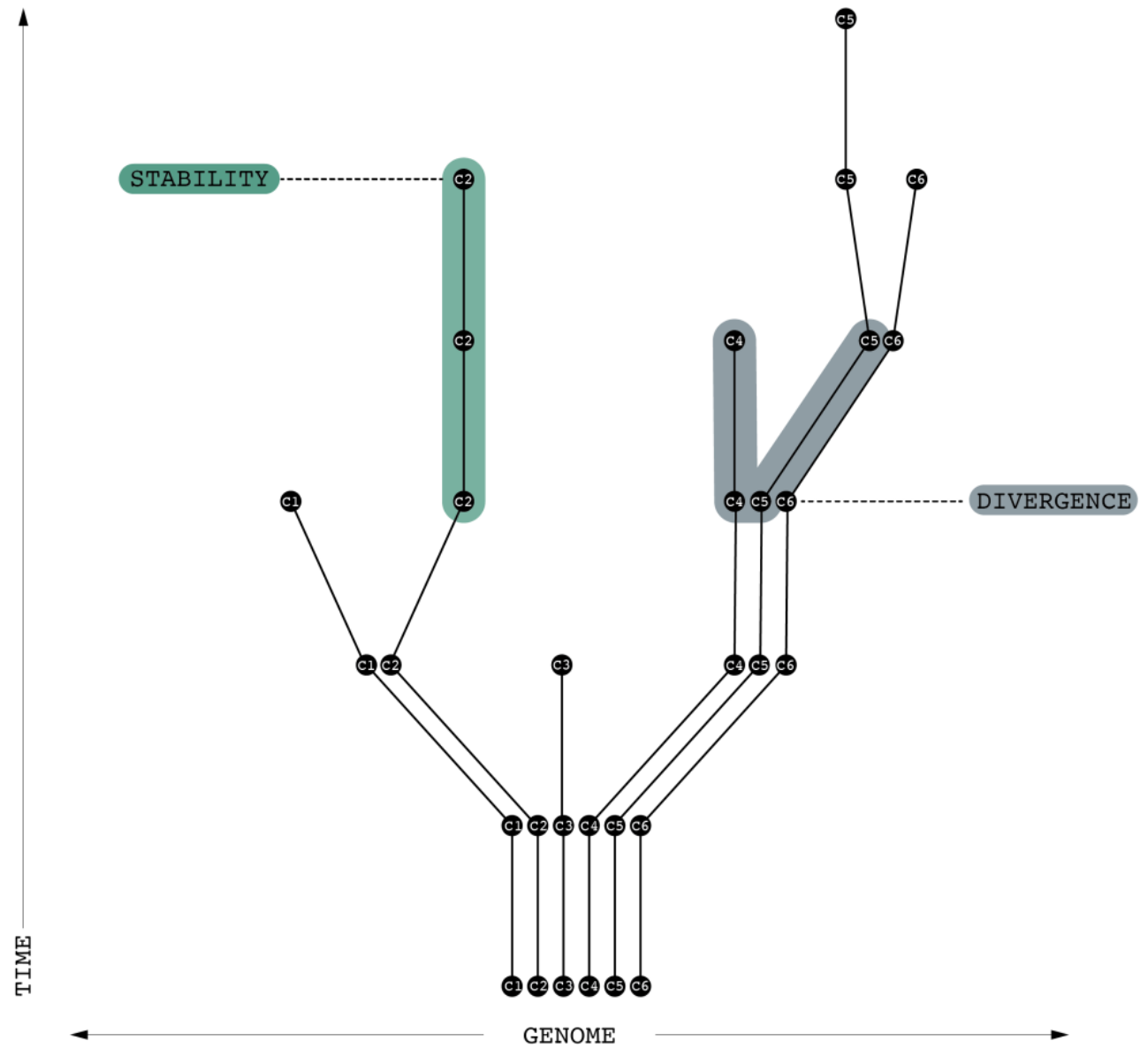

Figure 6: Urban Genome Trajectories

Figure 7 depicts the impact of signal S from c1 to c2. c2's genome is modified so that its similarity to c1's genome is increased, hence the bFdist() between c1 and c2 decreases over time - they converge. 


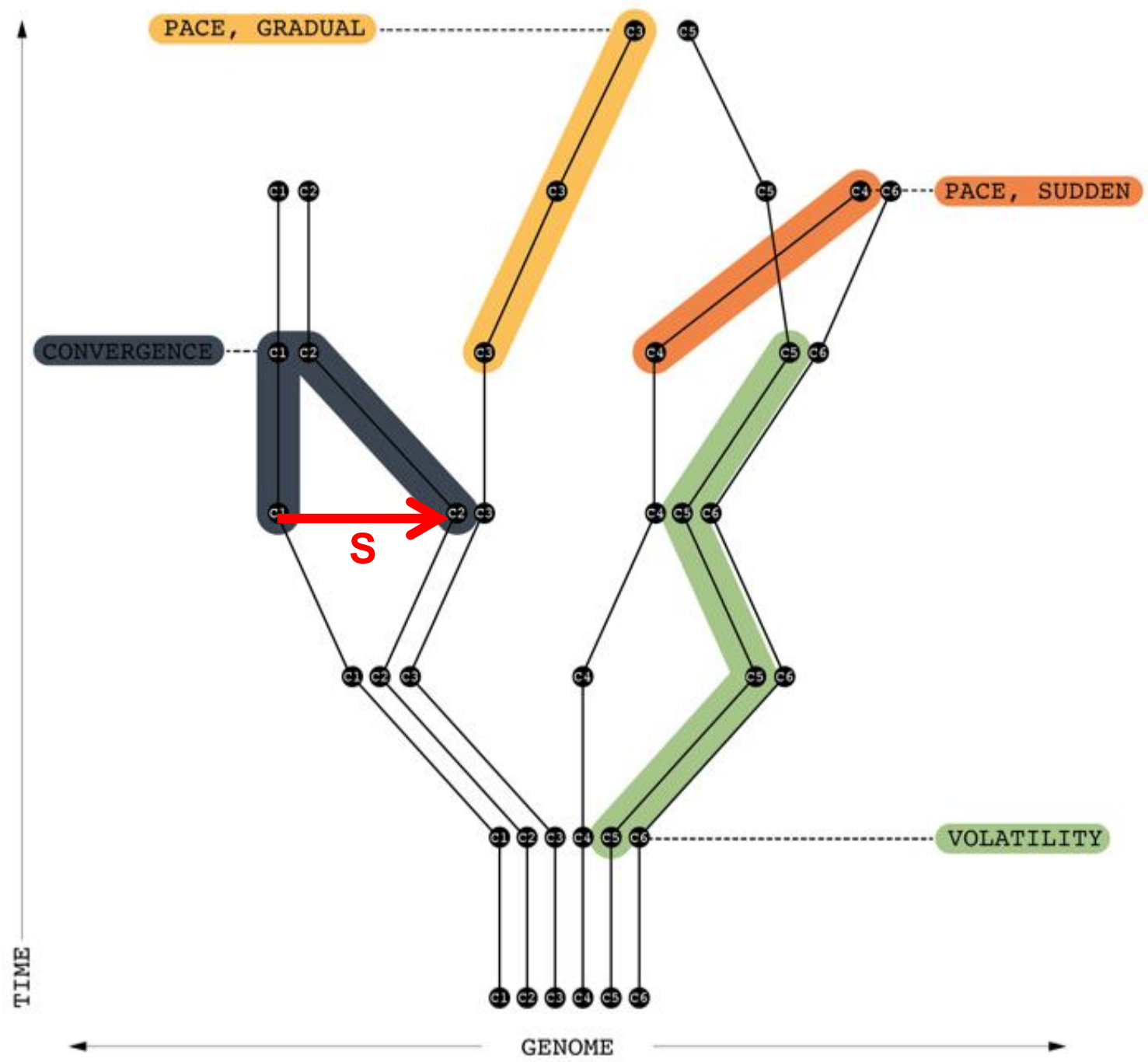

Figure 7: Signal Induced Convergence

Consider two spatial areas that contain the same types of elements, i.e., groups, activities and forms, but differ in the frequency with which they appear. For example, a gentrified town in the country may contain the same types of elements as a neighbourhood in a big city, but differ in the overall size or frequency of the elements, i.e., more of each of the common forms, groups and activities. Are these two spatial areas the same? Or consider the same spatial area whose elements do not change over time but the size or frequency does. For example, an ethnic neighbourhood, such as Italian or Greek, attracts greater numbers of the same forms, activities and groups over time. Is this the same neighbourhood?

To account for these types of scenarios, we define an alternative Fdist which we refer to as the "weighted distance metric" wFdist. wFdist takes into account the frequency with which elements appear in a set of formemes. If two sets of formemes have the same elements, then bFdist will determine that they are the same, i.e., zero distance between them. But if one set of formems have a greater frequency of elements than the other, then the distance will be greater than zero. 


$$
\begin{aligned}
& \Sigma_{\mathrm{e} \in \operatorname{Elements}(F 1, F 2)} \min (\mathrm{Fsize}(\mathrm{F} 1, \mathrm{e}), \operatorname{Fsize}(F 2, \mathrm{e})) \\
& \operatorname{wFdist}\left(\mathrm{F}_{1}, \mathrm{~F}_{2}\right)=1- \\
& \Sigma_{\mathrm{e} \in \operatorname{Elements}(\mathrm{F} 1, \mathrm{~F} 2)} \max (\mathrm{Fsize}(\mathrm{F} 1, \mathrm{e}), \operatorname{Fsize}(\mathrm{F} 2, \mathrm{e}))
\end{aligned}
$$

Where Elements $\left(F_{1}, F_{2}\right)$ is the set of all elements contained in $F_{1}$ and $F_{2}$

$$
=F_{1}[p] \cup F_{2}[p] \cup F_{1}[g] \cup F_{2}[g] \cup F_{1}[a] \cup F_{2}[a]
$$

We define two additional distance metrics focused on Group and Activity.

gdist(g1, g2): measures the distance between two groups, g1 and g2. The lower the distance, the greater the similarity between the groups.

$$
\begin{array}{ll}
\text { Axiom 1: Reflexivity } & \operatorname{gdist}(\mathrm{g}, \mathrm{g})=0 \\
\text { Axiom 2: Symmetry } & \operatorname{gdist}(\mathrm{g} 1, \mathrm{~g} 2)=\operatorname{gdist}(\mathrm{g} 2, \mathrm{~g} 1) \\
\text { Axiom 3: Subadditivity } & \operatorname{gdist}(\mathrm{g} 1, \mathrm{~g} 2)+\mathrm{gdist}(\mathrm{g} 2, \mathrm{~g} 3) \geq \operatorname{gdist}(\mathrm{g} 1, \mathrm{~g} 3)
\end{array}
$$

$\operatorname{adist}(\mathrm{x}, \mathrm{y})$ : measures the distance between two types of activities, a1 and a2. The lower the distance, the greater the compatibility between the activities.

Axiom 1: Reflexivity

Axiom 2: Symmetry

Axiom 3: Subadditivity

$$
\begin{gathered}
\operatorname{adist}(\mathrm{a}, \mathrm{a})=0 \\
\operatorname{adist}(\mathrm{a} 1, \mathrm{a} 2)=\operatorname{adist}(\mathrm{a} 2, \mathrm{a} 1) \\
\operatorname{adist}(\mathrm{a} 1, \mathrm{a} 2)+\operatorname{adist}(\mathrm{a} 2, \mathrm{a} 3) \geq \operatorname{adist}(\mathrm{a} 1, \mathrm{a} 3)
\end{gathered}
$$

\section{Spatial Distance}

Variation in a spatial area's genome may be due to its closeness to other spatial areas; a type of "spill over" effect. To support variation propositions based on spatial distance, we introduce the concept of distance between spatial areas.

\begin{tabular}{|l|l|}
\hline Relationship & Description \\
\hline distanceC $\left(c_{i}, c_{j}, t\right)$ & distance between the centroids of $c_{i}$ and $c_{j}$ \\
\hline distanceB $\left(c_{i}, c_{j}, t\right)$ & shortest distance between the borders of $c_{i}$ and $c_{j}$ \\
\hline
\end{tabular}

The same axioms hold for distanceB.

6. Evolutionary Trajectories 
In previous sections, the concept of evolutionary trajectory was introduced. In this section we formalize the concept of a trajectory using graph terminology.

The Gpath predicate captures the existence of a path between any two signatures:

GPath(c1, t, c2, t') is true if there exists a path that links $\operatorname{SIG}(\mathrm{c} 1, \mathrm{t})$ to $\operatorname{SIG}\left(\mathrm{c} 2, \mathrm{t}^{\prime}\right)$ in the evolution tree

Where
Axiom: Reflexivity
GPath $(\mathrm{c}, \mathrm{t}, \mathrm{c}, \mathrm{t})=$ True
Axiom: Symmetry
$\operatorname{GPath}\left(\mathrm{c} 1, \mathrm{t}, \mathrm{c} 2, \mathrm{t}^{\prime}\right)=\operatorname{GPath}\left(\mathrm{c} 2, \mathrm{t}^{\prime}, \mathrm{c} 1, \mathrm{t}\right)$
Axiom: Transitivity If GPath(c1, t, c2, t') $\wedge$ GPath(c2, t', c3, t'’) Then GPath(c1, t, c3, t'’)

If we assume there exists a single phylogenetic urban lineage tree, that is a common lineage to which all urban forms can be connected, GPath would be unnecessary as any node (i.e., genome) in the tree can be reached from any other node, ignoring directionality. But it is possible several trees co-exist, for example, as central American cities may have evolved separately to some degree from their European counterparts.

We define fPathU which determines whether two genomes that are connected (GPath) contain the same formeme $\mathrm{f}$ :

$\mathrm{fPathU}\left(\mathrm{c} 1, \mathrm{t}, \mathrm{c} 2, \mathrm{t}^{\prime}, \mathrm{f}\right)$ is true if $\operatorname{GPath}\left(\mathrm{c} 1, \mathrm{t}, \mathrm{c} 2, \mathrm{t}^{\prime}\right)$ is true $\wedge \mathrm{f} \in \mathrm{UG}(\mathrm{c} 1, \mathrm{t}) \wedge \mathrm{f} \in \mathrm{UG}\left(\mathrm{c} 2, \mathrm{t}^{\prime}\right)$

Where

Axiom: Reflexivity fPathU(c, t, c, t, f $)=$ True

Axiom: Symmetry $\quad$ PathU(c1, t, c2, t', f $)=$ fPathU(c2, t', c1, t, f)

Axiom: Transitivity If fPathU(c1, t, c2, t', f) and fPathU(c2, t', c3, t', f)

Then fPathU(c1, t, c3, t', f)

We define fPathH similarly but with $\mathrm{f} \in \mathrm{HG}(\mathrm{c} 1, \mathrm{t}) \wedge \mathrm{f} \in \mathrm{HG}\left(\mathrm{c} 2, \mathrm{t}^{\prime}\right)$

In order to capture the concept of phylogenetic lineage and inheritance, we introduce a restricted version of path, a directed path, where a directed path exists between two signatures if there exists a GPath, and the first genome is an ancestor of the second.

$\operatorname{DPath}\left(\mathrm{c} 1, \mathrm{t}, \mathrm{c} 2, \mathrm{t}^{\prime}\right)$ is true if $\mathrm{t}<\mathrm{t}^{\prime}$ and $\operatorname{SIG}(\mathrm{c} 1, \mathrm{t})$ is an ancestor of $\operatorname{SIG}\left(\mathrm{c} 2, \mathrm{t}^{\prime}\right)$

Where

Axiom: Reflexivity DPath $(\mathrm{c}, \mathrm{t}, \mathrm{c}, \mathrm{t})=$ True

Axiom: Asymmetry DPath(c1, t, c2, t') $\neq \operatorname{DPath}\left(\mathrm{c} 2, \mathrm{t}^{\prime}, \mathrm{c} 1, \mathrm{t}\right)$ for $\mathrm{c} 1 \neq \mathrm{c} 2$

Axiom: Transitivity If DPath(c1, t, c2, t') and DPath(c2, t', c3, t'') Then DPath(c1, t, c3, t'') for $\mathrm{t}<\mathrm{t}^{\prime}<\mathrm{t}^{\prime}$,

Similarily, we define fDpathU which determines whether two genomes that are connected (DPath) contain the same formeme $\mathrm{f}$ : 
fDPathU(c1, t, c2, t', F) is true if DpathU(c1, t, c2, t') is true

$\wedge \mathrm{f} \in \mathrm{UG}(\mathrm{c} 1, \mathrm{t}) \wedge \mathrm{f} \in \mathrm{UG}\left(\mathrm{c} 2, \mathrm{t}^{\prime}\right)$

Where

Axiom: Reflexivity fDPathU $(\mathrm{c}, \mathrm{t}, \mathrm{c}, \mathrm{t}, \mathrm{f})=$ True

Axiom: Asymmetry fDPathU(c1, t, c2, t', f) $=$ fDPathU $\left(c 2, t^{\prime}, c 1, t, f\right)$ for $\mathrm{c} 1 \neq \mathrm{c} 2$

Axiom: Transitivity If fDPathU(c1, t, c2, t', f) and fDPathU(c2, t', c3, t', f) Then

fDPathU $\left(\mathrm{c} 1, \mathrm{t}, \mathrm{c} 3, \mathrm{t}^{\prime}, \mathrm{f}\right)$ for $\mathrm{t}<\mathrm{t}^{\prime}<\mathrm{t}^{\prime}$,

We define fDPathH similarly but with $\mathrm{f} \in \mathrm{HG}(\mathrm{c} 1, \mathrm{t}) \wedge \mathrm{f} \in \mathrm{HG}\left(\mathrm{c} 2, \mathrm{t}^{\prime}\right)$

Finally, we introduce the concept of an environmentally stable trajectory. We define the environment of some spatial area $\mathrm{c}$ as stable between times $\mathrm{t}$ and $\mathrm{t}^{\prime}$, where $\mathrm{t}<\mathrm{t}^{\prime}$, for some threshold $\mathrm{k}_{\mathrm{s}}$, if the Fdist of the two sets of Signals is less than s:

Given: $\operatorname{SIG}(\mathrm{c}, \mathrm{t})=\left\langle\mathrm{U}, \mathrm{H}, \mathrm{S}>\wedge \mathrm{SIG}\left(\mathrm{c}, \mathrm{t}^{\prime}\right)=<\mathrm{U}^{\prime}, \mathrm{H}^{\prime}, \mathrm{S}^{\prime}>\right.$

$\operatorname{Estable}\left(\mathrm{c}, \mathrm{t}, \mathrm{t}^{\prime}\right)=$ True if Fdist $\left(\mathrm{S}[\mathrm{f}], \mathrm{S}^{\prime}[\mathrm{f}]\right) \leq \mathrm{k}_{\mathrm{s}}$, else False

\section{Formeme Survival}

Formemes may reproduce at different rates. And as this occurs, the distribution of formemes in the total population of c's will change. Some variants will cover a wider swathe of spaces, others will dwindle: the city evolves.

In evaluating formeme survival, reproductive strategies are crucial concepts, elaborated further in Part III. We represent the set of strategies as $\mathcal{R}$.

$\mathcal{R}$ : Is the set of selection strategies that can be used to propagate a formeme or genome.

We represent the application of a replication strategy as:

$\mathrm{UG}\left(\mathrm{c}, \mathrm{t}^{\prime}\right)=\operatorname{replicate}(\mathrm{c}, \mathrm{t}, \mathrm{st})$

where "replicate" applies replication strategy st to the genome UG(c,t) and $s t \in \mathcal{R}$

To unpack the notion of differential reproduction, we need to develop a framework for discussing sets of formemes and urban genomes: many areas (c's) formed in different or similar ways.

We define a genomeSet as the set of all usage genomes $\mathrm{HG}(\mathrm{c}, \mathrm{t})$ where $\mathrm{c}$ is a member of a set of nonoverlapping places $\mathrm{C}$ and $\mathrm{t}$ is a member of a set of times $\mathrm{T}$.

$$
\operatorname{genomeSet}(\mathrm{C}, \mathrm{T})=\{\mathrm{HG}(\mathrm{c}, \mathrm{t}) \mid \mathrm{c} \in \mathrm{C} \text { and } \mathrm{t} \in \mathrm{T}\}
$$

The notion of genomeSet allows us to examine formemes distributed across locations.

We define formemeCount $(\mathrm{C}, \mathrm{T}, \mathrm{F})$ to be the number of members of genomeSet $(\mathrm{C}, \mathrm{T})$ that contain the same set of formemes $\mathrm{F}$. 


$$
\text { formemeCount }(\mathrm{C}, \mathrm{T}, \mathrm{F})=|\{\mathrm{HG}(\mathrm{c}, \mathrm{t}) \mid \mathrm{F} \subseteq \mathrm{HG}(\mathrm{c}, \mathrm{t}) \wedge \mathrm{c} \in \mathrm{C} \wedge \mathrm{t} \in \mathrm{T}\}|
$$

Formemes will exhibit variation over both time and space. The question is which will survive? For any formemeSet, the survival rate of a subset of formemes is given by the total members for a genome set at a given time that contain $\mathrm{F}$, divided by the number of members at a previous time:

$$
\begin{aligned}
& \text { formemeSurvivalRate }\left(\mathrm{C}, \mathrm{F}, \mathrm{t}, \mathrm{t}^{\prime}\right)=\text { formemeCount }\left(\mathrm{C}, \mathrm{t}^{\prime}, \mathrm{F}\right) / \text { formemeCount }(\mathrm{C}, \mathrm{t}, \mathrm{F}) \\
& \text { where } \mathrm{t}^{\prime}>\mathrm{t} \text {. }
\end{aligned}
$$

If formemeSurvivalRate is less then 1 , then the occurrence of the formeme set $\mathrm{F}$ is decreasing over time, and as the survival rate approaches 0 , a set of formemes approach extinction.

Finally, we can extend the notion of survivalRate to activities as follows:

$$
\text { activitySurvivalRate }\left(c, a, t, t^{\prime}\right)=\operatorname{size}\left(c, t^{\prime}, a\right) / \operatorname{size}(c, t, a)
$$

\section{Activity Costs and Recoding}

Our model of urban evolution provides a vocabulary for representing how and why various aspects of the urban environment replicate at different rates in different places. To formulate such a model, we need to cover some additional ground: activity costs and recoding. These terms give us language to explain how and when $U$ changes (or persists), and to characterize the difference between genomes that are geared toward restrictive and highly specific uses/users (those that impose clearly defined costs on specific uses and users) vs. those that are more flexible and less clearly defined.

We define the cost of performing some type of activity $a$ in reference to a set of formemes $\mathrm{F}$ by the following function:

activity $\operatorname{Cost}(\mathrm{F}$, a) where $\mathrm{F}$ is a set of formemes.

Cost is indicative of resistance. If we are speaking of a dance club, this means that it requires relatively little cost to use it as such. Conversely, violating its code can come at great cost. Somebody who tries to drive a semi-truck onto a narrow road meets resistance from the physical form; somebody who attempts to walk into a nightclub in violation of the dress code meets resistance from the bouncer; and somebody who attempts to undertake activities in violation of a zoning designation meets resistance from city inspectors. These are examples of activities for which their costs depend on the genome.

Proposition:

$$
\text { if } \mathrm{e} \in \mathrm{F}[\mathrm{a}] \text { and } \mathrm{e}^{\prime} \notin \mathrm{F}[\mathrm{a}] \text {, then } \operatorname{activity} \operatorname{Cost}\left(\mathrm{F}, \mathrm{e}^{\prime}\right)>\operatorname{activity} \operatorname{Cost}(\mathrm{F}, \mathrm{e}) \text {. }
$$

In other words, it will generally be more difficult to perform an activity in a formeme set for something it is not currently programmed.

We define aggregateActivityCost as the sum of activityCost of all activities a in formeme set F: 


$$
\text { aggregateActivityCost }(\mathrm{F})=\sum_{\mathrm{e} \in \mathrm{F}[\mathrm{a}]} \operatorname{activityCost}(\mathrm{F}, \mathrm{e})
$$

It can be the case that it is more difficult for one group to participate in an activity than other. One example is the direct or indirect segregation of activities. Assume that there is a single golf course in c, and membership/usage is controlled by a membership committee who limit membership to their own group. Attempts by members of other groups to join or use the golf course are rejected by the committee. Once in a while an outsider may be admitted if they have high enough prestige or donate substantial sums of money. We capture the concept of differential cost of activities by groups in the context of a set of formemes $\mathrm{F}$ as:

groupActivityCost $(\mathrm{F}, \mathrm{a}, \mathrm{g})$ where $\mathrm{a}$ is the activity performed by group $\mathrm{g}$ in $\mathrm{c}$ at time $\mathrm{t}$.

The genome for a space c can remain stable over time, or it can change. When genomes change, they have been recoded. Recoding an area's genome means that variant formemes have been retained there. For example, a location with a warehouse programmed for shipping and receiving that changes to a dance club has been recoded. Recoding involves changing the value for any element of $U$. We can identify a specific occurrence of recoding as follows:

Recoding: $\mathrm{UG}\left(\mathrm{c}, \mathrm{t}_{\mathrm{i}}\right) \neq \mathrm{UG}\left(\mathrm{c}, \mathrm{t}_{\mathrm{j}}\right)$ for $\mathrm{t}_{\mathrm{j}}>\mathrm{t}_{\mathrm{i}}$

Here the fact that $\mathrm{UG}\left(\mathrm{c}, \mathrm{t}_{\mathrm{j}}\right)$ differs from $\mathrm{UG}\left(\mathrm{c}, \mathrm{t}_{\mathrm{i}}\right)$ indicates that location $c$ at some later time $\mathrm{t}_{\mathrm{j}}$ has been recoded in some fashion.

Recoding is not always easy, because encoding a space $c$ imposes a cost structure favouring or hindering some uses and users. The physical form of a warehouse, for example, is relatively conducive to dancing to loud music, but also to shipping and receiving. It offers substantial open space and sound dampening. Likewise, a building code imposes costs on changing the physical materials and arrangement of a form. Similarly, a dress code imposes relatively high costs on users who attempt to violate it. Variation in recoding costs generates the path dependencies out of which evolutionary historical trajectories arise.

Accordingly, we represent Recoding Cost as:

$$
\text { recodeCost(F, F') }
$$

where recodeCost denotes the cost of recoding a set of formemes F into F', in other words the cost of changing the form, activity and/or users in any of the formemes. recodeCost $(\mathrm{F}, \mathrm{F})$ could be viewed as the sum of the independent recodings of the formemes in $F$. Note that recodeCost $(F, F)=0$.

\section{Discussion and Conclusion}

Our model of urban evolution is driven by the distinction between: the Urban Genome U, which defines the sedimented forms, and the groups and activities toward which they are oriented; the human actors $\mathrm{H}$ which realize the actual forms, and their actual groups and activities; and Signals $\mathrm{S}$, the Formemes received by the spatial area. This distinction allows us to formulate evolutionary rules (see 
part III), for example about how the frequency of signals, such as the global rise of coffee culture, can impact $\mathrm{H}$; or how changes in $\mathrm{H}$, such as new uses of buildings, can impact $\mathrm{U}$.

Central to this model is the Formeme. A Formeme encapsulates the binding force between form, groups, and activities. It is the foundational component that underlies $\mathrm{U}, \mathrm{H}$ and $\mathrm{S}$. It is Formemes that are communicated by Signals. It is Formemes that define both $\mathrm{U}$ and $\mathrm{H}$.

The model raises a number of questions, which we address by way of conclusion.

\section{What is the appropriate size of a spatial area $c$ ?}

By design we do not constrain the size of a spatial area. A spatial area can be as small (or large) as a building, a city block, a neighbourhood, a census track, or the entire city. The spatial areas chosen depends on the focus of the analysis. For example, we may want to study the evolution of the groups and activities of a single neighbourhood independent of others. Or we may want to study the impact of signals on several contiguous neighbourhoods, each represented by a separate $\mathrm{c}$, but each sending signals to each other. Or we may want to study the neighbourhoods separately and in aggregate, where the neighbourhood spatial areas are contained within the city spatial area.

\section{What are the possible elements of the components: $P, G$ and A?}

The answer depends on what is being studied. For example, if we are studying the evolution of Pueblo Societies between A.D. 600 and 1300 (Cockburn et al., 2013), the elements of P, G, and A would be very different than if we were studying a rural village today. The choice of elements depends upon what is being studied and the hypotheses driving the study; the elements chosen to model the same spatial area for the same time period may differ from one researcher to another, reflecting their own research hypotheses. The elements chosen to model a set of spatial areas at one level may also differ from the elements used to model an aggregation of these spatial areas, i.e., neighbourhood level elements versus city level elements. Perhaps part of the evolutionary process is selecting and/or aggregating elements to be used at an aggregate spatial level.

\section{Does the model scale?}

It depends on what is meant by scale. Certainly, spatial areas can be as small as needed, such as a city block, and as large as a city. And they can be analysed simultaneously, as the model supports as many levels of spatial aggregations as needed, and alternative aggregations. Moreover, elements can differ between levels of abstraction, allowing for aggregation and abstraction of elements, thereby making for a powerful approach to modelling and analysing scaling.

\section{How does this relate to agent-based urban simulations?}

One can view an agent-based simulation as generating the data necessary to construct the Urban Signature. An event in an agent based simulation generates a quintuple comprised of a time, a spatial area, a group (which can be an individual), an activity (the event) and a form (where or on what the 
activity has been performed). ${ }^{3}$ These event generated quintuples can then be used to generate the Usage Genome H. In other words, based on these events we can construct a spatial area's signature for different periods of time. We can then study how $\mathrm{H}$ changes over time, and how it in turn changes the genome $\mathrm{U}$.

A Signature can represent the form, activities and groups at some space and time, but where does evolution appear?

With the Signature defined, we can now explore the evolution of urban areas by generating and analysing the changes in an area's signature over time through the basic evolutionary algorithm of variation-selection-retention, as elaborated in Part III. Assuming a source of event data, either from a simulation as discussed above, or from datasets such as Yelp, Foursquare, Google, national censuses etc., for each combination of spatial and time period we can generate a Signature. We can then analyse a spatial area's signature over time to see how $\mathrm{H}$ and $\mathrm{S}$ interact and lead to changes in $\mathrm{U}$. In other words, the Signature provides snapshots of what we believe are the key components of an urban area, which we can use either to infer rules of urban evolution, or confirm/refute hypothesized rules of urban evolution.

Part I of our Model of Urban Evolution situated our work with the broader context of the study of cities and theories of urban and cultural evolution. Part II has formally defined our model of a city, and in fact any urban, suburban or rural area. These two parts prepare the way for part III where we introduce our rules of urban evolution.

\section{Acknowledgements}

This paper is part of the Urban Genome Project (UGP), which is supported by a University of Toronto Connaught Global Challenge Award and the School of Cities Urban Challenge Fund. We are grateful to the ongoing dialogue and editorial feedback from our collaborators in the UGP, and in particular to Scott Sanner, Ultan Byrne and Rob Wright.

${ }^{3}$ We have omitted discussion of Signals for simplicity. 


\section{References}

Brown, R. (2013). Explanation in social science. Routledge.

Cockburn, D., Crabtree, S. A., Kobti, Z., Kohler, T. A., \& Bocinsky, R. K. (2013). Simulating social and economic specialization in small-scale agricultural societies. Journal of Artificial Societies and Social Simulation, 16(4), 4.

Silver, D., Adler, P., and Fox, M.S., (2020), “Towards a Model of Urban Evolution: Part I: Context”.

Simon, H. A. (1952). A formal theory of interaction in social groups. American Sociological Review, 17(2), 202211. 